\title{
Nasal dorsum skin expansion for reconstruction of saddle nose due to gunshot injury: A case report
}

\author{
Serdar Ozturk MD ${ }^{1}$, Fatih Zor MD $^{2}$, Mustafa Sengezer MD ${ }^{1}$
}

\begin{abstract}
S Ozturk, F Zor, M Sengezer. Nasal dorsum skin expansion for reconstruction of saddle nose due to gunshot injury: A case report. Can J Plast Surg 2005;13(3):148-150.

Saddle nose deformity due to gunshot injury is a challenging problem for the maxillofacial surgeon. Because of the severe damage to the soft and bony tissues, the reconstructive options are very limited. In the present case report, a saddle nose deformity sustained from gunshot injury was reconstructed with a porous polyethylene nasal implant after a successful expansion of the nasal dorsum skin. Healing was uneventful at two-year follow-up, with superior patient satisfaction. Nasal dorsum skin expansion should be considered as an option in the reconstruction of moderately sized soft tissue deficits of the nose.
\end{abstract}

\section{Expansion cutanée au niveau de l'arête du nez pour corriger un nez camus causé par un projectile d'arme à feu : Rapport de cas}

Key Words: Expansion; Nasal reconstruction; Saddle nose

$\mathrm{N}$ Tasal reconstruction after gunshot injury continues to be a challenging problem for the reconstructive surgeon. The concomitant goals of reconstruction are the restoration of an aesthetic, functional and durable nose with minimization of the donor-site morbidity (1). The location of the nose makes the reconstructive procedure more difficult, because there are not enough local flap donor sites. Additionally, maxillofacial gunshot injuries result in extensive composite soft and bony tissue loss.

Here, we present a patient whose saddle nose deformity resulting from a gunshot injury was reconstructed by expanding the nasal dorsum skin. To the best of our knowledge, this is the first nasal expansion procedure used in reconstructing a saddle nose deformity due to gunshot injury.

\section{CASE PRESENTATION}

A 21-year-old man suffering from a maxillofacial gunshot injury due to attempted suicide was admitted to the Department of Plastic and Reconstructive Surgery at Gülhane Military Medical Academy, Ankara, Turkey. On admission, physical examination of the patient revealed maxillary, mandibular and naso-orbitoethmoid fractures with extensive soft tissue loss at the exit site of the bullet on the radix of the nose (Figure 1). The patient was operated on, and open reduction and rigid internal fixation were performed for the facial fractures. Medial canthopexy and left orbital floor reconstruction with a high-density porous polyethylene sheet (Medpor, Porex Surgical, USA) were performed during the same session.

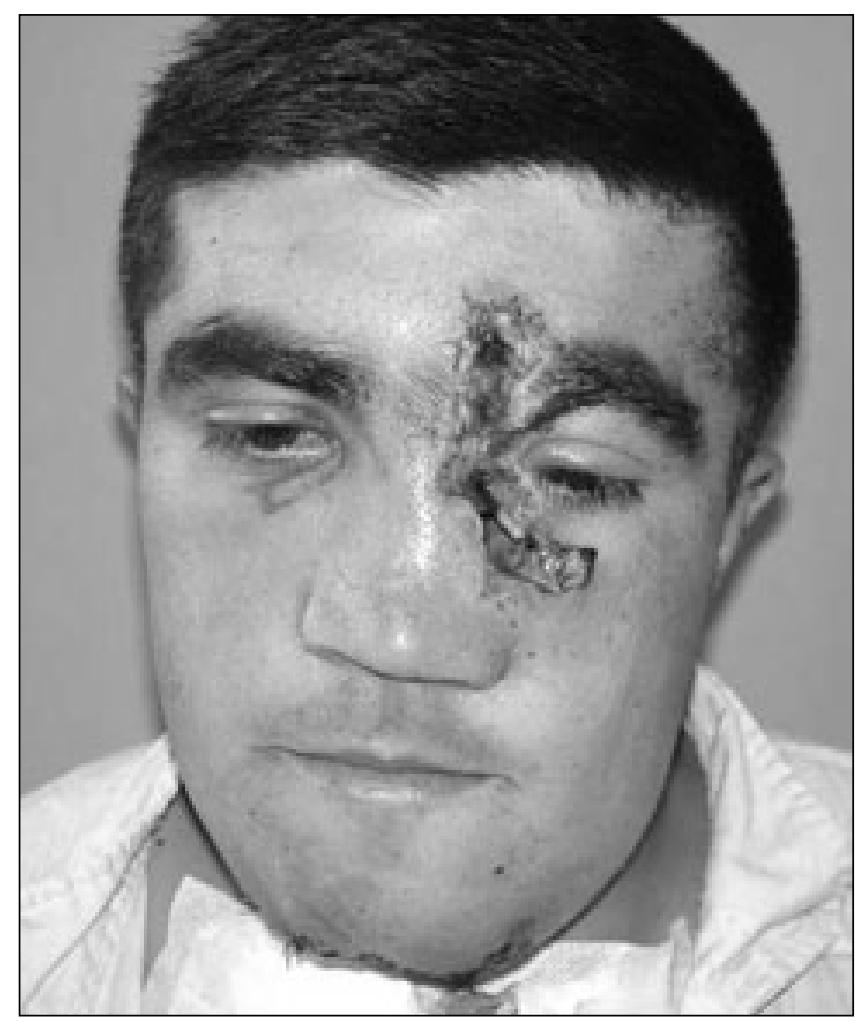

Figure 1) Patient with maxillofacial gunshot injury, showing the entrance and exit of the bullet

${ }^{1}$ Department of Plastic and Reconstructive Surgery, Gülhane Military Medical Academy, Ankara; ${ }^{2}$ Plastic and Reconstructive Surgery Clinic, Corlu Military Hospital, Tekirdag, Turkey

Correspondence: Dr Fatih Zor, Corlu Askeri Hastanesi, Plastik Cerrahi Klinigi, 59850 Corlu, Tekirdag, Turkey.

Telephone 90-282-650-1051,fax 90-282-652-1846, e-mail fatihzor@yahoo.com 


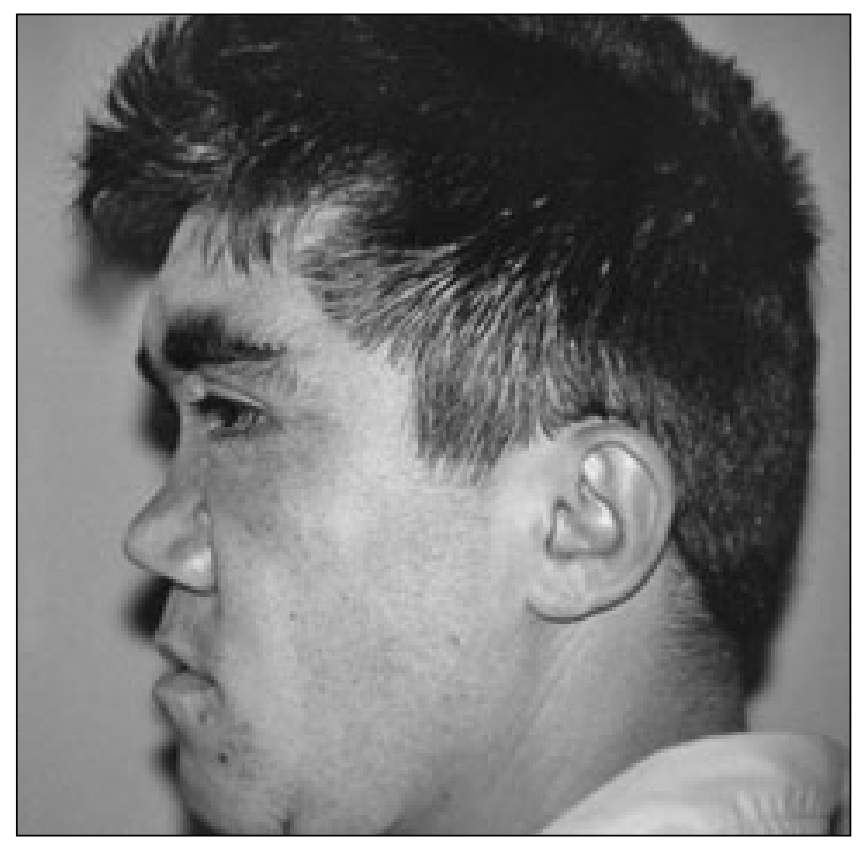

Figure 2) Saddle nose deformity after open reduction and rigid internal fixation

The patient gained acceptable facial contour and symmetry with normal occlusion except for the remaining saddle nose deformity. Loss of skeletal support with overlying soft tissue deficit was found at the upper two-thirds of the nose (Figure 2). Six months following the initial surgery, nasal dorsum expansion was decided on. The patient was operated on and an $8 \mathrm{~mL}$ rectangular tissue expander was placed under the skin of the nasal dorsum through an incision from the existing scar at the frontal region. The expander was filled with $14 \mathrm{~mL}$ of saline over a three-week period. Following successful expansion, the definitive treatment was performed (Figure 3). The expander and its reservoir were removed and the nose was skeletonized through an intercartilaginous incision and the preexisting scar at the glabella. The intraoperative exploration showed that the left nasal bone was totally absent. A $1.5 \mathrm{~mm}$ thick Medpor sheath measuring $2 \mathrm{~cm} \times 2 \mathrm{~cm}$ in dimension was used to replace the missing left nasal bone. To restore the nasal height, a Medpor nasal dorsum implant was placed through the tunnel created after removal of the expander. Additionally, another thin Medpor implant of $5 \mathrm{~mm} \times 12 \mathrm{~mm}$ in dimension was inserted into the columella vertically for tip support and projection. The incisions were closed and a dorsal nasal splint was applied for 12 days. The final appearance of the patient was good and the patient was satisfied with the result (Figure 4). No complications were encountered at the two-year follow-up.

\section{DISCUSSION}

Nasal reconstruction remains a complex and challenging field for the plastic surgeon. The long-term results of nasal reconstruction are judged by the quality of the nasal skin, nasal contour and the nasal scars. The reconstructive procedure is decided according to the defect and the tissue needed. The most popular option for nasal soft tissue replacement is the forehead flap. A forehead flap is a good alternative for soft tissue coverage because of good skin colour and texture match,

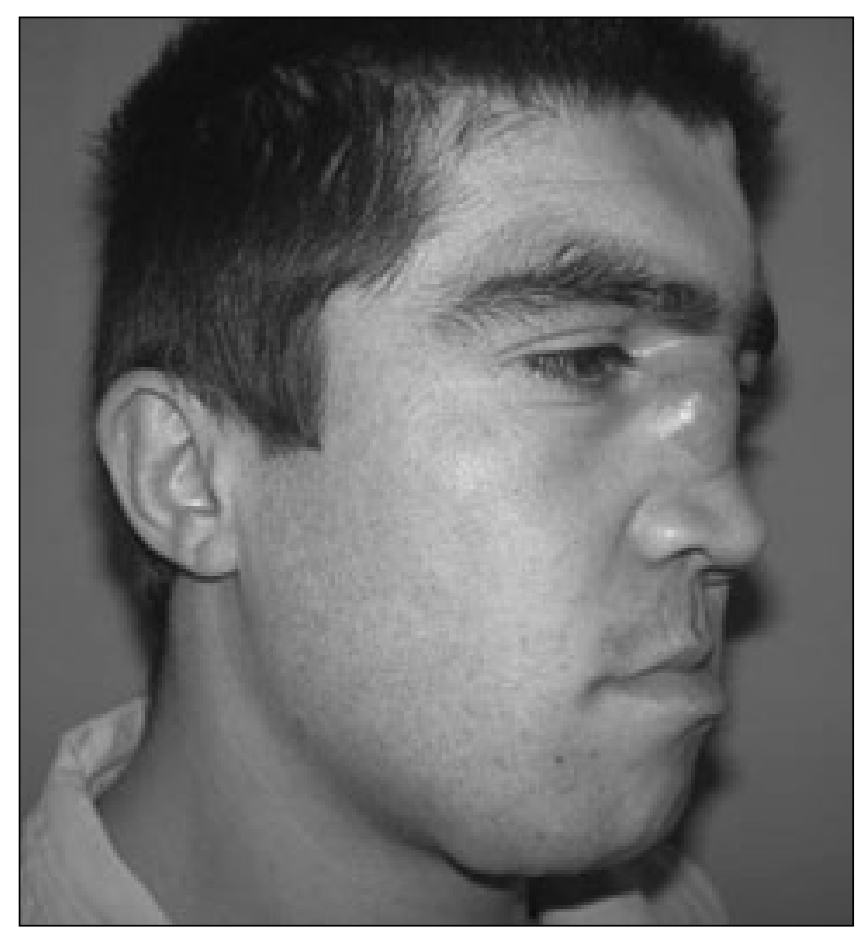

Figure 3) Nasal dorsum skin expanded with an $8 \mathrm{~mL}$ rectangular expander

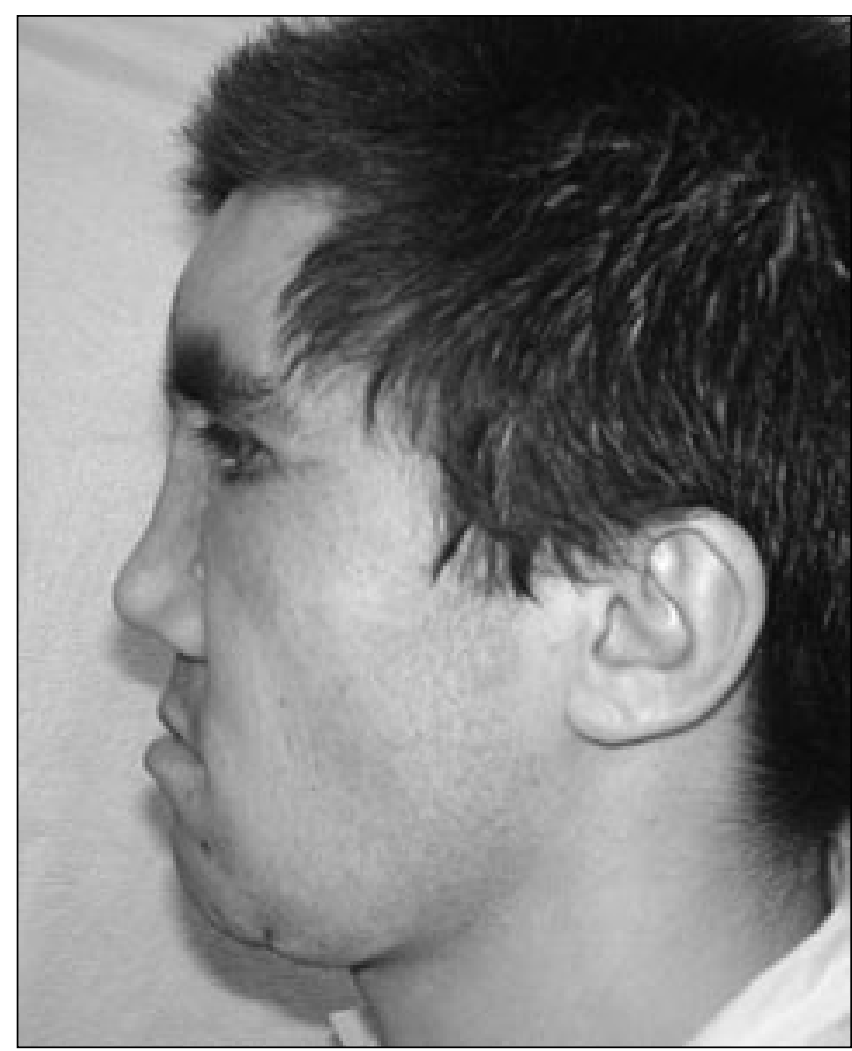

Figure 4) Postoperative view of the patient at two-year follow-up

lack of hair and reliable vascular supply (1). A forehead flap may also be used as an expanded flap, which lowers the donor site morbidity by supplying extra soft tissue (2). The use of an expanded paramedian forehead flap has many advantages, 
including additional length, improved vascularity, improved flap thinning and decreased donor site morbidity (3). However, this flap results in an obvious scar on the forehead area, which is the main disadvantage of this procedure. In the present case, the gunshot injury resulted in extensive scar formation including the glabellar and supraorbital regions. Therefore, the forehead flap was not a reliable choice for the patient.

The patient in the present article had severe saddle nose deformity secondary to maxillofacial gunshot injury. The defect included both the bony framework and cartilaginous septum of the nose, necessitating a three-dimensional reconstruction. Cantilever grafts to the nasal dorsum are currently a widely accepted and reliable technique for reconstructing the nasal framework. A cantilever graft may be either autologous bone or cartilage, or alloplastic materials such as porous polyethylene, vitallium or titanium mesh $(1,4)$. Calvarial bone grafts have some disadvantages such as donor site complications, inability to bend the bone and additional operating time (5). Of the alloplastic materials, porous polyethylene is one of the most popular (6). In our patient, porous polyethylene implants were used successfully for both the columellar support and the dorsal augmentation. Moreover, the missing left nasal bone was also replaced by a Medpor sheet implant.

The present patient had a moderate soft tissue deficit due to soft tissue shrinkage at the nasal dorsum. The nasal reconstruction was postponed and performed during the second

\section{REFERENCES}

1. Bikhazi NB, Chow AW, Maas CS. Nasal reconstruction using a combination of alloplastic materials and autogenous tissues: A surgical alternative. Laryngoscope 1997;107:1086-93.

2. Argenta LC, Watanabe MJ, Grabb WC. The use of tissue expansion in head and neck reconstruction. Ann Plast Surg 1983;11:31-7.

3. Adamson JE. Nasal reconstruction with the expanded forehead flap. Plast Reconstr Surg 1988;81:12-20.

4. Cheney ML, Gliklich RE. The use of calvarial bone in nasal reconstruction. Arch Otolaryngol Head Neck Surg 1995;121:643-8. stage because of the contaminated nature of the wound. As with all alloplastic materials, the Medpor implant should be covered by thick, well-vascularized, healthy skin. The expansion of nasal dorsal skin provides enough soft tissue with original skin colour and texture match. The expander may be inserted through a preexisting scar without any need for a new incision. Even if there is no scar, the expander can be inserted through a glabellar incision, and the resulting scar is quite acceptable (7).

Nasal dorsum expansion has rarely been used in congenital deformities of the nose (7), but it has never been used in the reconstruction of gunshot injuries of the nose. Because the quality of the skin and nose is not altered in congenital deformities, successful expansion is easily achieved. However, gunshot injuries generally create major defects in the bony and soft tissues of the maxillofacial area, especially at the central region. This makes expansion more difficult, but these problems can be resolved by appropriate surgical technique.

\section{CONCLUSIONS}

Nasal dorsum expansion remains a good alternative in patients with moderately sized soft tissue insufficiency, and should be kept in mind for selected patients with moderately sized saddle nose deformities. It also provides high-quality skin for coverage of an alloplastic material.

5. Frodel JL Jr, Marentette LJ, Quatela VC, Weinstein GS. Calvarial bone graft harvest. Arch Otolaryngol Head Neck Surg 1993;119:17-23.

6. Turegun M, Sengezer M, Guler M. Reconstruction of saddle nose deformities using porous polyethylene implant. Aesthetic Plast Surg 1998;22:38-41.

7. van Der Meulen JC, van Adrichem LN, Vaandrager JM. The nasal dorsum as a donor site for the correction of alar, lobular, and columellar malformations. Plast Reconstr Surg 2001;107:676-86. 